\title{
Prevalence of Anterior Open Bite among Male Saudi Children in Eastern Province
}

\author{
Authors \\ Albraithen Abdulrahman, Aljohani Mohammed, Alfaleh Saleh, Alsumihan Haitham, \\ Alkhaldi Khalid, Aldawish Abdulrahman
}

\begin{abstract}
The aim of this study was to determine the prevalence of anterior open bite among male Saudi children in eastern province. A clinical examination of 319 children, with age range from 9 to 11 years old. The mean age was 10 years. Also, a short presentation were given to the children. Participants included 319 children with mean age of 10 years. They were consisted of Angle's Class I was $83.7 \%$, Class II was $11.9 \%$ and Class III was 4.4\%. The anterior open bite was found in 28 child (8.8\%) in all Classes. The prevalence of anterior open bite in the examined children was $8.8 \%$ in al malocclusion Classes. This will help decision maker of providing adequate number of Orthodontists based on evidence to offer necessary treatment for those children.
\end{abstract}

Keywords: Anterior, open-bite, children, dental, orthodontics.

\section{INTRODUCTION}

During the past 20 years, orthodontic treatment for adults has become much more commonplace. The proportion of orthodontic patients in the United States who are adults rose from approximately 5 percent in 1970 to a peak of 25 percent in 1990. During the past few years, the proportion of adult patients has dropped to around 15 percent, although the absolute number has remained constant, at about 600,000 . In some areas of the country, particularly areas with large numbers of retirees, adults may constitute more than half of all orthodontic patients. Major reasons for the dramatic rise in adult orthodontic treatment include increased social awareness of the availability of orthodontic treatment for adults, an increased appreciation of how orthodontics can facilitate other dental treatment to maintain the dentition, and improvements in orthodontic appliances.

A key factor in an adult's decision to seek orthodontic treatment is the amount and quality of information available.

Although most orthodontic treatment is performed by specialists, the general dentist plays an important role in establishing contact between a prospective patient and an orthodontist. It is therefore essential for general dentists to understand the indications and contraindications for, as well as the consequences of, orthodontic therapy.

The aim of this study was to examine the presence of anterior open bite in eastern province in Saudi Arabia and among male schools children.

Since this relationship is known to be important, and due to lack of studies in our region, a necessity 
was needed to further examine the relationship between oral hygiene and SES.

Therefore, The aim of the study was to determine the status of the oral health of children compared to the SES of the parents in the city of Dammam, Saudi Arabia.

\section{Material and Methodology}

This was a cross sectional study conducted by two dental interns at the College of Dentistry, University of Dammam as graduation project.

The study was done on target group consisting of school student children.

The oral health awareness program and data collection occurred at the following two venues: Abdullah Bin Abbas and Saqer Al-Jazera primary schools in Dammam, Eastern region, Saudi Arabia.

During the field trip to the designated venues, a short oral-hygiene presentation was delivered by one of the dental Intern to the children to educate them about the right way of brushing and flossing. Also, some valuable information about the type of food and the risk of sticky food was presented to them as well.

A pamphlet, demonstrating brushing and flossing technique was printed and distributed in all two schools. At the end of the lecture each child received a pamphlet and clinical examination .

The examination was conducted using a penlight and tongue blade. Angles classification was examined in which one intern examined participants with a help of other intern, also the overbite, Open bite, cross bite and midline shifting was examined.

The data was collected using the clinical finding according to indices mentioned above.

The dependent variable was the angle's classification and open bite, The independent variables were over bite, midline shifting and cross bite.

The study comprised of an educational presentation using a laptop and projector. The lecture included general information about dental caries and periodontal disease and how to maintain good oral hygiene. Following each lecture the students were divided into small groups, each group assigned to one of the to demonstrate the proper way of brushing and flossing using jaw models and toothbrush.

\section{Results}

Participants included 319 children with mean age of 10 years. Class I angles classification was found in 267 child $(84.5 \%)$ class II was found in 38 child $(11.9 \%)$ class III was found in 14 child (4.4\%). (table-1)

\begin{tabular}{|c|cc|cc|cc|}
\hline Variables & \multicolumn{6}{|c|}{ Frequencies } \\
\hline \multirow{2}{*}{ School code } & \multicolumn{2}{|c|}{ ABA } & \multicolumn{2}{|c|}{ SAJ } & \multicolumn{2}{|c|}{ Total } \\
& $\mathrm{N}$ & $(\%)$ & $\mathrm{N}$ & $(\%)$ & $\mathrm{N}$ & $(\%)$ \\
\hline $\begin{array}{c}\text { Number of } \\
\text { participants }\end{array}$ & 216 & $(67.7)$ & 103 & $(32.3)$ & 319 & $(100)$ \\
\hline Angle's classification & & & & & & \\
Class I & 180 & $\mathbf{( 8 3 . 3 )}$ & $\mathbf{8 7}$ & $(\mathbf{8 4 . 5 )}$ & $\mathbf{2 6 7}$ & $(\mathbf{8 3 . 7 )}$ \\
Class II & 26 & $(12)$ & 12 & $(11.6)$ & 38 & $(11.9)$ \\
Class III & 10 & $(4.6)$ & 4 & $(3.9)$ & 14 & $(4.4)$ \\
& & & & & & \\
\hline
\end{tabular}

Table-1: Angle's classification, Frequencies and modal distributions.

Bold font: Modal distribution.

-ABA: Abdullah Bin Abbas primary school.

*SAJ: Sagr Al-Jazeera primary school.

The anterior open bite was found in 28 child (8.8\%). (table-2)

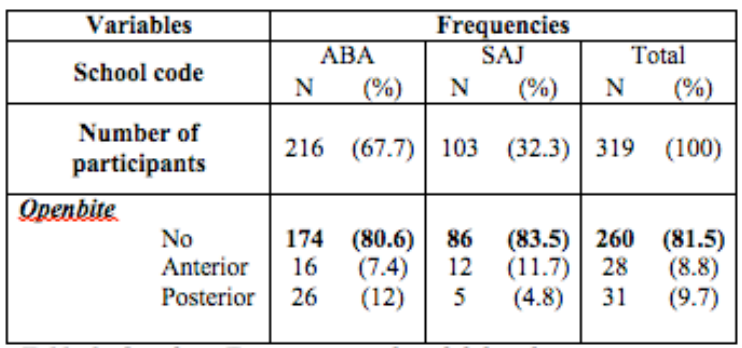

Table-2: Openbite, Frequencies and modal distributions.

Bold font: Modal distribution.

-ABA: Abdullah Bin Abbas primary school.

-SAJ: Sagr Al-Jazeera primary school.

\section{Discussion}

A study in the city of Recife, Brazil in 2008 showed that there is a relationship between non-nutritive sucking habits and the presence of anterior open bite.

Among 4-6 years children the result of the study revealed significant reduction in anterior open bite $(\mathrm{p}<0.001)$ and slight increase in the prevalence of posterior cross bite. Both occlusal traits were associated with a previous history of sucking habits. Other study in Lagos, Nigeria in 2010 the aim of study was to determine the prevalence of oral habits and there affects on occlusion. 
Cross sectional study of 928 children aged 4-15 years. There was 360 child $(34.1 \%)$ of total children examined exhibited one form of oral habits. most common habits observed was digit sucking which was observed in $17 \%$ of the children. Anterior open bite was observed in $12.5 \%$ of habit children.

Other Study conducted in Northampton shire UK 2010, compare occlusal characteristics of persistent digit suckers with those a group of individuals who reported never to have sucked their thumb or finger. 39 digit suckers were compared to 36 non-suckers the odds of reduced overbite being present were significantly higher in the digit sucking group compared to non-suckers. the prevalence of anterior open bite was higher in the digit suckers $(p<0.001)$.

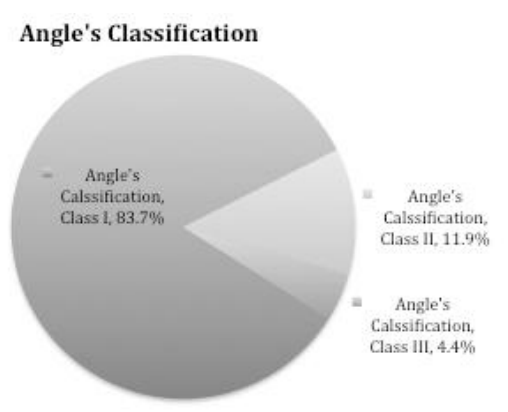

\section{Conclusion}

Further studies are recommended to assess associated risk factors causing this type of malocclusion and apply possible preventive treatment to avoid this problem from occurring.

Early detection for any type of malocclusion is necessary to prevent or reduce the psychological and financial burdens that result from malocclusion and orthodontics treatment.

\section{References}

1. Antanas Šidlauskas, Kristina Lopatiene: The prevalence of malocclusion among 7-15year-old Lithuanian schoolchildren, Medicina (Kaunas) 2009;45(2).

2. Tschill P, Bacon W, Sonko A. Malocclusion in the deciduous dentition of Caucasian children. Eur J Orthod 1997;19:361- 367.

3. Eva Josefsson, Krister Bjerklin and Rune Lindsten: Malocclusion frequency in Swedish and immigrant adolescentsinfluence of origin on orthodontic treatment need: European Journal of Orthodontics 29 (2007) 79-87.

4. Declan Millett and Richard Welbury, Orthodontics and Pesiatric Dentistry, $1^{\text {st }}$ edition; 2000 page 55. 